\title{
Oxidant stress regulatory genetic variation in recipients and donors contributes to risk of primary graft dysfunction after lung transplantation
}

\author{
Edward Cantu, MD, ${ }^{a}$ Rupal J. Shah, MD, ${ }^{\text {b,c }}$ Wei Lin, $\mathrm{PhD},{ }^{\mathrm{c}}$ Zhongyin J. Daye, PhD, MS, \\ Joshua M. Diamond, MD, MSCE, ${ }^{\text {b,c }}$ Yoshikazu Suzuki, MD, MS, ${ }^{a}$ John H. Ellis, BA, ${ }^{a}$ \\ Catherine F. Borders, BA, ${ }^{a}$ Gerald A. Andah, BA, ${ }^{\mathrm{a}}$ Ben Beduhn, BA, ${ }^{\mathrm{a}}$ Nuala J. Meyer, MD, MS, ${ }^{\mathrm{b}, \mathrm{c}}$ \\ Melanie Ruschefski, BA, ${ }^{\mathrm{b}, \mathrm{c}}$ Richard Aplenc, MD, MS, ${ }^{\mathrm{c}, \mathrm{d}}$ Rui Feng, $\mathrm{PhD},{ }^{\mathrm{c}}$ and \\ Jason D. Christie, MD, MS, ${ }^{\text {b,c }}$ for the Lung Transplant Outcomes Group Investigators
}

\begin{abstract}
Objective: Oxidant stress pathway activation during ischemia reperfusion injury may contribute to the development of primary graft dysfunction (PGD) after lung transplantation. We hypothesized that oxidant stress gene variation in recipients and donors is associated with PGD.
\end{abstract}

Methods: Donors and recipients from the Lung Transplant Outcomes Group (LTOG) cohort were genotyped using the Illumina IBC chip filtered for oxidant stress pathway genes. Single nucleotide polymorphisms (SNPs) grouped into SNP sets based on haplotype blocks within 49 oxidant stress genes selected from gene ontology pathways and literature review were tested for PGD association using a sequencing kernel association test. Analyses were adjusted for clinical confounding variables and population stratification.

Results: Three hundred ninety-two donors and 1038 recipients met genetic quality control standards. Thirty percent of patients developed grade 3 PGD within 72 hours. Donor NADPH oxidase 3 (NOX3) was associated with PGD $(P=.01)$ with 5 individual significant loci $(P$ values between .006 and .03$)$. In recipients, variation in glutathione peroxidase (GPX1) and NRF-2 (NFE2L2) was significantly associated with PGD ( $P=.01$ for both). The GPX1 association included 3 individual loci ( $P$ values between .006 and .049$)$ and the NFE2L2 association included 2 loci $(P=.03$ and .05$)$. Significant epistatic effects influencing PGD susceptibility were evident between 3 different donor blocks of NOX3 and recipient NFE2L2 $(P=.026, P=.017$, and $P=.031)$.

Conclusions: Our study has prioritized GPX1, NOX3, and NFE2L2 genes for future research in PGD pathogenesis, and highlights a donor-recipient interaction of NOX3 and NFE2L2 that increases the risk of PGD. (J Thorac Cardiovasc Surg 2015;149:596-602)

See related commentary on pages 602-3.

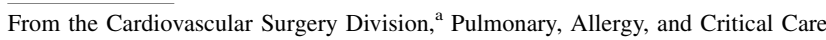
Division, ${ }^{\mathrm{b}}$ and Center for Clinical Epidemiology and Biostatistics, ${ }^{\mathrm{c}}$ University of Pennsylvania Perelman School of Medicine; and Division of Oncology, ${ }^{\mathrm{d}}$ Department of Pediatrics, Children's Hospital of Philadelphia, Philadelphia, Pa.

Funding sources: National Institutes of Health Heart, Lung and Blood Institute grants HL087115, HL081619, HL096845, HL115354, HL114626, HL116656, and HL090021; and Robert Wood Johnson Foundation grant RWJ11642. Rui Feng has received grant support from the National Institutes of Health General Medical Sciences (ROIGM088566)

Disclosures: Nuala J. Meyer has received lecturing fees from the American Thoracic Society and the American College of Chest Physicians. All other authors have nothing to disclose with regard to commercial support.

Edward Cantu, Rupal J. Shah, Rui Feng, and Jason D. Christie contributed equally to this work.

Received for publication April 9, 2014; revisions received Aug 19, 2014; accepted for publication Sept 23, 2014; available ahead of print Oct 17, 2014.

Address for reprints: Edward Cantu, MD, Division of Cardiovascular Surgery, University of Pennsylvania Perelman School of Medicine, 3400 Spruce St, 6 Silverstein Pavilion, Philadelphia, PA 19104 (E-mail: edward.cantu@uphs.upenn.edu).

0022-5223/\$36.00

Copyright (C) 2015 by The American Association for Thoracic Surgery

http://dx.doi.org/10.1016/j.jtcvs.2014.09.077

Primary graft dysfunction (PGD) is a form of acute lung injury that develops within 72 hours of lung transplantation. It is defined by the presence of hypoxemia and radiographic infiltrates in the allograft, ${ }^{1}$ and is the major cause of death in the early posttransplant period. ${ }^{2}$ PGD affects $10 \%$ to $30 \%$ of all patients receiving lung transplantation, ${ }^{3}$ and is associated with an increased risk of bronchiolitis obliterans syndrome, prolonged hospitalization, and increased short- and long-term mortality. ${ }^{1,3-5}$

Although the pathophysiology of PGD is incompletely understood, ischemia reperfusion injury leading to activation of the oxidant stress pathway is believed to be a major contributor to its development. ${ }^{6}$ In support of this notion, Williams, and colleagues ${ }^{7}$ identified antioxidant system dysfunction before lung transplantation that persisted for up to a year after transplantation. Furthermore, the 


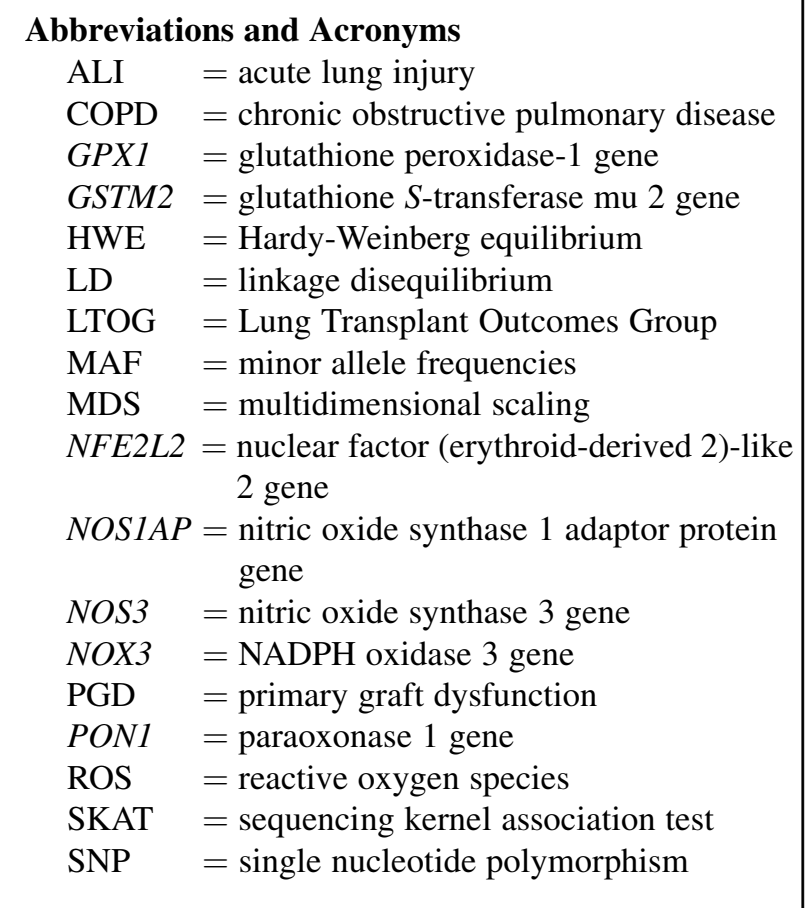

antioxidant $N$-acetylcysteine was protective against graft dysfunction in a small randomized trial. ${ }^{8}$ In addition, targeted delivery of catalase, an antioxidant enzyme, reduced ischemia reperfusion injury in an experimental model of lung transplantation. ${ }^{9}$ These and other studies provide evidence that oxidative stress is an important mediator of lung allograft dysfunction after transplantation.

The oxidant stress pathway is rich in genetic variation, believed to be to the result of evolutionary pressures from infectious and environmental stimuli. Previous studies have implicated genetic variation in oxidant stress genes altering the risk of acute lung injury (ALI).$^{10-12}$ In this study, we sought to identify donor and recipient variation in oxidative stress genes associated with PGD using a large multicenter cohort study and a candidate gene platform. This study has previously been registered as clinicaltrials.gov NCT00457847.

\section{METHODS}

\section{Study Population and Data Collected}

Participants were selected from the Lung Transplant Outcomes Group (LTOG), which is a multicenter, prospective cohort study of lung transplant recipients that has been previously described. ${ }^{13-17}$ The University of Pennsylvania institutional review board (Federal-wide Assurance no. 00004028) approval and informed written consent was obtained before recruitment. Consecutive individuals transplanted between January 1, 2002, and December 31, 2009, from 10 LTOG centers were enrolled. Clinical data were collected prospectively as described elsewhere. ${ }^{18,19}$ PGD grade was determined using the consensus definition of the International Society of Heart and Lung Transplantation using 2 blinded readers as previously described. ${ }^{20,21}$ We used any grade 3 PGD occurring within the first 72 hours after lung transplantation as our primary definition of PGD (noted as PGD henceforth). ${ }^{21}$ Potential confounding variables including both recipient and donor characteristics were tested for their association with PGD. Recipient age, predisposing diagnosis, and use of cardiopulmonary bypass were significant at the .05 level and thus were included in the genetic models. ${ }^{18}$

\section{Collection and Processing of Biological Samples}

Whole blood collected before organ procurement (donor) or organ implantation (recipient) was centrifuged, and buffy coat fractions were aliquoted and stored at $-80^{\circ} \mathrm{C}$ until DNA extraction using the Qiagen Qiamp 96 blood kit (Qiagen, Valencia, CA). Negative controls were included with all DNA extraction runs. Extracted DNA from PGD and non-PGD individuals were plated together on each 96-well microplate, and laboratory personnel were unaware of the PGD status of each sample at the time of laboratory analysis.

\section{Genotyping and Quality Control}

We used the HumanCVD BeadChip (IBC chip), a custom 50,000 single nucleotide polymorphism (SNP) genotyping array designed to assay SNPs in candidate genes and pathways affecting cardiovascular, pulmonary, inflammatory, and metabolic phenotypes (llumina, Inc, San Diego, Calif). ${ }^{22}$ The array was designed to evaluate all nonsynonymous coding SNPs with minor allele frequencies (MAF) greater than 0.01 , as well as provide coverage for several loci with MAF greater than 0.02 of potential importance to cardiac, pulmonary, and metabolic phenotypes. ${ }^{22}$ Quality control thresholds for each SNP to be included in the analysis included genotyping call greater than or equal to $95 \% ; \chi^{2}$ testing of Hardy-Weinberg equilibrium (HWE) on the whole population yielding a $P$ value of $10^{-6}$ or greater; and MAF greater than or equal to 0.01 overall. We sought to apply a computational methodology (SNP set analysis) that incorporated oxidant stress as a biologically plausible mediator of PGD. To accomplish this, we filtered the IBC BeadChip for 49 oxidant stress genes identified through a PubMed search conducted in May 2011 using the search terms "oxidant stress," "”polymorphism," "genetic" limited to human and manually curated search results. Identified genes were further expanded using gene ontology pathways (see the Online Data Supplement for the list of genes, Table E1).

After genotyping, outliers were detected and removed using a genome-wide similarity metric. ${ }^{23}$ Population stratification was determined using multidimensional scaling (MDS) analysis using all markers ${ }^{23}$ and the resulting components were used in adjustments for population stratification.

\section{SNP Set Analysis}

SNPs were grouped into sets based on haplotype blocks within 49 genes identified to be in the oxidant stress pathway. The haplotype blocks were initially determined using the confidence interval method ${ }^{24}$ implemented in Haploview, and small blocks were modified to include at least 3 common SNPs.

We used a logistic kernel machine method, sequencing kernel association test (SKAT), to test the joint effect of SNP sets on PGD. The method has previously been shown to have improved power to detect association by reducing the total number of tests being performed, jointly testing the multiple SNPs surrounding causal variants, and incorporating nonlinear and epistatic effects. ${ }^{25}$ Detailed methods of SNP set analyses are presented in Appendix E1. We first tested the associations between PGD and each recipient's SNP set and then between PGD and each donor's SNP set, adjusting for recipient age, recipient diagnosis, use of cardiopulmonary bypass, and population stratification. ${ }^{26}$

After donor and recipient genes with significant association were identified, we used the quadratic terms to test the interactions between significant matched donor and recipient SNP sets using SKAT. ${ }^{27}$ For 


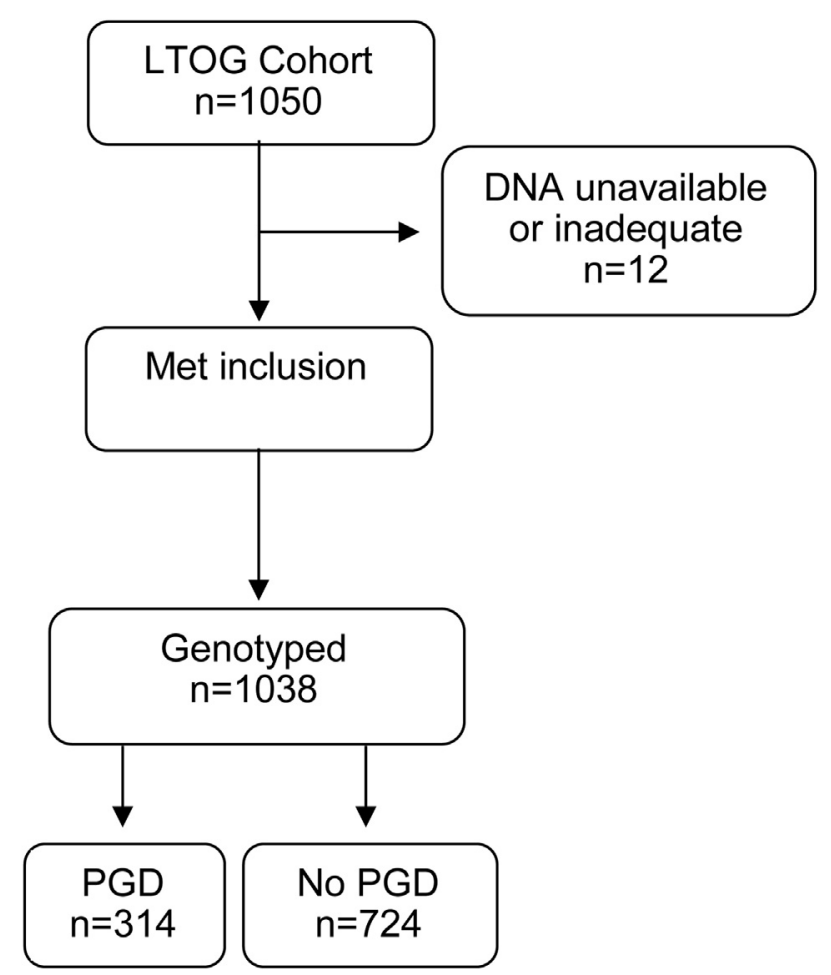

FIGURE 1. Enrollment design. LTOG, Lung Transplant Outcomes Group; $P G D$, primary graft dysfunction.

each interaction test of donor SNP set 1 and recipient SNP set 2, all pairwise cross products of SNPs within set 1 and SNPs within set 2 were included in the function $h$ of the model (Equation E1). We fitted a multivariate logistic model with coded SNPs as an approximation to the nonparametric function and the top SNPs that were most associated with PGD were chosen as covariates to be adjusted in the model for testing the nonlinear effect of gene-set interactions.

\section{RESULTS}

There were 1038 lung transplant recipients and 392 lung donors who met genetic quality control standards (Figure 1) with 338 representing a donor-recipient pair. Thirty percent (95\% confidence interval, 27.5, 33.0) of patients (314 of 1038) developed grade 3 PGD within 72 hours. Baseline demographics for the participants in the study are summarized in Table 1. Recipient race, pretransplant diagnosis, and use of cardiopulmonary bypass differed by PGD. These differences have previously been described as associated with PGD. ${ }^{3}$

Table 2 presents the results of the main effect SNP set associations. Four recipient genes were associated with increased risk of PGD: glutathione peroxidase (GPXI), an enzyme important in detoxification of hydrogen peroxide $(P=.01)$; nuclear factor (erythroid-derived 2)-like 2 (NFE2L2), encoding the NRF-2 transcription factor that upregulates expression of several phase I and phase II reactive oxygen species (ROS) detoxifying proteins (block $1, P=.024$; block 2, $P=.005$ ); there was also borderline significance for nitric oxide synthase 3 (NOS3), responsible for production of nitric oxide $(P=.028)$; and glutathione $S$-transferase mu 2 enzyme (GSTM2), which regulates glutathione production $(P=.048)$. Individual recipient SNPs that differed most between PGD and non-PGD included 3 SNPs within GPXI and 2 within NFE2L2. Within GPXI, PGD associations included 2 SNPs in tight linkage disequilibrium (LD), $\operatorname{rs} 3811699(P=.006)$ and rs1800668 $(P=.012)$, located in the $5^{\prime}$ promoter region and first exon, which have previously been described to have functional consequences in transcription, ${ }^{28}$ and rs9818758 $(P=.046)$ located in the intergenic region near GPX1, which has been associated with inflammatory bowel disease. ${ }^{29}$ Within NFE2L2, there were 2 SNPs located in the first intron that were significantly associated with PGD; rs6726395 $(P=.029)$ and rs1806649 $(P=.049)$. These SNPs were in moderate LD $\left(\mathrm{R}^{2}=0.35 ; \mathrm{D}^{\prime}=0.93\right)$ with SNPs previously reported to have function and ALI association by our group (Figure E1). ${ }^{10}$

In donors, NOX3 $(P=.01)$, nitric oxide synthase 1 adaptor protein (NOSIAP, $P=.048$ ), and paraoxonase 1 (PON1, $P=.03$ ) were associated with the development of PGD. Within NOX3, rs3749930, a coding nonsynonymous SNP had the strongest association with PGD $(P=.006)$. The SNP marks a G/T nucleotide conversion resulting in a threonine to lysine substitution at position 171 in a transmembrane portion of the NOX-3 protein. The variant Tallele resulting in a lysine was associated with a decreased risk of PGD compared with the ancestral $\mathrm{G}$ allele. In addition, several intronic SNPs within NOX3 were associated with increased risk of PGD.

Sensitivity analyses of individual donor and recipient SNPs with respect to cardiopulmonary bypass and idiopathic pulmonary fibrosis demonstrated only small effects on point estimates. Only 1 of the 10 variants (rs231948) demonstrated a change in the directionality of the risk (Table 3 and Table E3). These results suggest the effects of the individual SNPs are important and not the result of known unbalanced clinical risk factors.

Individual SNP interactions between the 338 matched donor-recipient pairs are presented in Figure 2. Within recipient NFE2L2, blocks 1 and 2 (5 kb and $34 \mathrm{~kb}$ in length) are separated by $10 \mathrm{~kb}$ with $1 \mathrm{SNP}$ in the intervening region not in LD with either block. Donor NOX3 was divided into 5 blocks. Block 1 was the largest of the blocks $(21 \mathrm{~kb})$ containing 14 SNPs with a 4-kb intervening region with 7 SNPs upstream of block 2. Table E2 displays the significant interactions that were detected between donor and recipient genes. As displayed in Figure 2, donor NOX3 block 3 and block 5 were demonstrated to have significant epistatic effects with recipient NFE2L2 blocks 1 and 1 and 2 in their association with the development of PGD $(P=.026$, $P=.017$, and $P=.031$, respectively). 
TABLE 1. Donor and recipient characteristics*

\begin{tabular}{|c|c|c|c|}
\hline & $\begin{array}{l}\text { No PGD } \\
(n=724)\end{array}$ & $\begin{array}{c}\text { PGD } \\
(\mathrm{n}=\mathbf{3 1 4})\end{array}$ & $P$ value \\
\hline Donor age, $\mathrm{y} \pm \mathrm{SD}$ & $34.48 \pm 14.31$ & $34.64 \pm 13.97$ & .872 \\
\hline Female donor, $\mathrm{n}(\%)$ & $277(38)$ & $136(43)$ & .128 \\
\hline Donor race, $\mathrm{n}(\%)$ & & & .965 \\
\hline White & $457(63)$ & $205(65)$ & \\
\hline African American & $145(20)$ & 59 (19) & \\
\hline Hispanic & $85(12)$ & $34(11)$ & \\
\hline Other & $30(4)$ & $13(4)$ & \\
\hline Recipient age, $\mathrm{y} \pm \mathrm{SD}$ & $54.02 \pm 12.91$ & $53.09 \pm 12.57$ & .277 \\
\hline Female recipient, n (\%) & $322(44)$ & $143(46)$ & .786 \\
\hline Recipient race, n (\%) & & & .001 \\
\hline White & $632(87)$ & $245(78)$ & \\
\hline African American & $49(7)$ & $46(15)$ & \\
\hline Hispanic & $24(3)$ & $14(4)$ & \\
\hline Other & $18(2)$ & $9(3)$ & \\
\hline Diagnosis, $\mathrm{n}(\%)$ & & & $<.001$ \\
\hline COPD & $109(15)$ & $26(8)$ & \\
\hline IPF & $282(39)$ & $177(56)$ & \\
\hline Other & $333(46)$ & $111(35)$ & \\
\hline Bilateral treatment, n (\%) & $73(10.1)$ & $29(9.2)$ & .758 \\
\hline CPB use, $n(\%)$ & $221(31)$ & $174(55)$ & $<.001$ \\
\hline
\end{tabular}

$P G D$, Primary graft dysfunction; $S D$, standard deviation; $C O P D$, chronic obstructive pulmonary disease; $I P F$, idiopathic pulmonary fibrosis; $C P B$, cardiopulmonary bypass. *Comparison of individual cohorts with and without donor/recipient pairing is available in the supplemental materials.

\section{CONCLUSIONS}

PGD is a complex trait that has been associated with both inherent donor and recipient clinical factors. ${ }^{3}$ In this study, we have defined both the main effects and the interactions in key oxidant stress genes from lung transplant donors and recipients that increase the risk of PGD after transplant, using SNP set analysis. Like most complex traits, PGD most likely involves many SNPs with modest effects; therefore this technique is particularly well suited. ${ }^{30}$ This study is the first to use these techniques in a lung transplant cohort, and our results identify that GPX1, NFE2L2, NOS3, GSTM2, NOX3, NOS1AP, and PON1 should be prioritized for future research efforts. Most importantly, the demonstration of donor-recipient interaction between putatively functional SNPs in genes encoding NOX3 and NRF2 (NFE2L2) should focus future research efforts on these mediators.

NFE2L2 encodes NRF-2, a zinc finger transcription factor responsible for the upregulation of several key reactive oxygen detoxification enzymes. ${ }^{31}$ A hypofunctioning promoter variant in NF2EL2 (rs6721961) has previously been show by our group to have an association with increased risk for ALI after major trauma. ${ }^{10}$ This variant and others previously described by our group are not contained within the IBC chip used in our current study. However, the individual SNPs within NFE2L2 described in our current study (rs6726395 and rs1806649) are
TABLE 2. Genes associated with primary graft dysfunction*

\begin{tabular}{clcc}
\hline Cohort & \multicolumn{1}{c}{ Gene } & P value & No. of SNPs \\
\hline Recipients & GPX1 block 1 & .014 & 8 \\
$(\mathrm{n}=1038)$ & NFE2L2 block 1 & .024 & 3 \\
& NFE2L2 block 2 & .005 & 13 \\
& NOS3 block 1 & .028 & 8 \\
& GSTM2 block 1 & .048 & 6 \\
Donors & NOX3 block 2 & .01 & 3 \\
$(\mathrm{n}=392)$ & NOX3 block 3 & .05 & 12 \\
& NOS1AP block 4 & .048 & 11 \\
& PON1 block 4 & .035 & 13 \\
Interaction & Donor NOX3 block 3 with & .026 & \\
$(\mathrm{n}=338)$ & recipient NFE2L2 block 1 & & \\
& Donor NOX3 block 5 with & .017 & \\
& recipient NFE2L2 block 1 & & \\
& Donor NOX3 block 5 with & .031 & \\
& recipient $N F E 2 L 2$ block 2 & & \\
\hline
\end{tabular}

$\overline{S N P \text {, Single nucleotide polymorphism. *Statistical tests of significance generated }}$ using the quadratic kernel function.

significantly associated with PGD in lung transplant recipients and are in moderate $\mathrm{LD}$ with the previously described promoter SNP not in the IBC chip (rs6721961, $\mathrm{D}^{\prime}=1 ; \mathrm{R}^{2}=0.118$ and $\mathrm{D}^{\prime}=1 ; \mathrm{R}^{2}=0.052$, respectively; Figure E1, B). Variation in this gene in lung transplant recipients may increase susceptibility to $\mathrm{PGD}$ by reducing transcription of ROS detoxifying enzymes, and a resultant dampened oxidant stress response.

Interactions between recipient NFE2L2 and donor NOX3 were also associated with PGD risk. However, the functional consequences of the Thr171Lys substitution (rs3749930) in NOX3 is unknown and the function of the NOX3 intronic variants (rs231956, rs13207865, rs23948, and rs1546894) have thus far not been described. Because any hypothesized mechanism behind the interaction of recipient NFE2L2 and donor NOX3 on PGD susceptibility is speculative at this time, fine mapping of variants and/or cellular functional studies aimed at clarifying this finding are logical next research steps. Our study is useful to prioritize these 2 genes for further research into their function in increased risk of PGD.

GPX1 is an intracellular antioxidant enzyme that reduces harmful hydrogen peroxide to water. ${ }^{32}$ Genetic polymorphisms in GPX1 have been demonstrated to affect transcription and alter response to vascular oxidant stress and risk of cardiovascular disease in humans. ${ }^{28}$ In our study, 3 GPX1 SNPs (rs1800668, rs9818758, rs3811699) were significantly associated with PGD. Two of the 3 SNPs (rs1800668, rs3811699) are in tight $\mathrm{LD}\left(\mathrm{D}^{\prime}=1\right.$, $\mathrm{R}^{2}=0.88$, Figure E1) and have previously been shown to enhance oxidant injury in cell culture through decreased expression of GPX1 in the setting of oxidant stress. ${ }^{28}$ Our results demonstrate protective effects associated with these 3 SNP (rs1800668, rs9818758, rs3811699) minor alleles, indicating that either lower GPX1 expression is protective 
TABLE 3. Individual single nuclear polymorphisms associated with primary graft dysfunction

\begin{tabular}{|c|c|c|c|c|c|c|c|c|}
\hline Cohort & SNP & MA & MAF_A & OR & $\mathbf{9 5} \% \mathrm{CI}$ & $P$ value & Gene & Location \\
\hline \multirow[t]{5}{*}{ Recipient } & rs9818758 & A & 0.13 & 0.74 & $0.54,0.99$ & .048 & GPX1 & Intergenic \\
\hline & rs1800668 & $\mathrm{T}$ & 0.25 & 0.74 & $0.58,0.94$ & .012 & $G P X 1$ & UTR \\
\hline & rs3811699 & G & 0.26 & 0.72 & $0.57,0.91$ & .006 & $G P X 1$ & $5^{\prime}$ upstream \\
\hline & rs6726395 & $\mathrm{T}$ & 0.43 & 0.79 & $0.64,0.98$ & .029 & $N F E 2 L 2$ & Intron \\
\hline & rs1806649 & A & 0.18 & 0.76 & $0.58,0.99$ & .049 & $N F E 2 L 2$ & Intron \\
\hline \multirow[t]{5}{*}{ Donor } & rs3749930 & $\mathrm{T}$ & 0.06 & 0.38 & $0.20,0.76$ & .006 & NOX3 & Coding nonsynonymous \\
\hline & rs 231956 & $\mathrm{C}$ & 0.53 & 1.49 & $1.05,2.12$ & .024 & NOX3 & Intron \\
\hline & rs 13207865 & $\mathrm{~T}$ & 0.29 & 1.57 & $1.06,2.33$ & .024 & NOX3 & Intron \\
\hline & rs 231948 & $\mathrm{~T}$ & 0.54 & 0.57 & $0.3,1.0$ & .037 & NOX3 & Intron \\
\hline & rs1546894 & A & 0.02 & 0.31 & $0.11,0.89$ & .029 & NOX3 & Intron \\
\hline
\end{tabular}

$S N P$, Single nucleotide polymorphism; $M A$, minor allele; $M A F \_A$, minor allele frequency of those affected; $O R$, odds ratio; $C I$, confidence interval; $A$, adenine; $T$, thymine; $U T R$, untranslated region; $G$, guanine; $C$, cytosine.

or that the putative functional inference from previous studies does not apply to pulmonary ischemia reperfusion injury. Therefore, future study is warranted in suitable models that apply to PGD.

There are several limitations of this study. First, although several of our implicated variants have suggested function in regulating transcription from previous studies, it is not possible to establish functional causation with our study design. However, our results serve to prioritize these specific oxidant stress genes for future study. Second, gaps in our knowledge on oxidant stress gene inducers, regulators, and modulators may have led us to exclude genes with important function in regulating oxidative stress. ${ }^{30}$ We designed a strategy that was as inclusive as possible, relying both on existing gene ontology pathways as well a comprehensive literature search. In addition, SNP set methods as we have used them assume that SNPs within known genes associate with a complex trait, an approach that ignores potential trait-associated SNPs that are not located within genes. ${ }^{30}$ Third, although we did not perform a simple adjustment for multiple comparisons in our postanalysis $P$ values (such as a Bonferroni adjustment), SNP set methods do not require postanalysis multiple comparison adjustment, as the method accounts for the number of comparisons. ${ }^{25}$ In addition, our methods did not use multiple adjustments for donor-specific factors given the limited information available. Our findings have not been replicated in an independent dataset. Unfortunately, there is no existing cohort to validate our multicenter findings available at this time. Work is

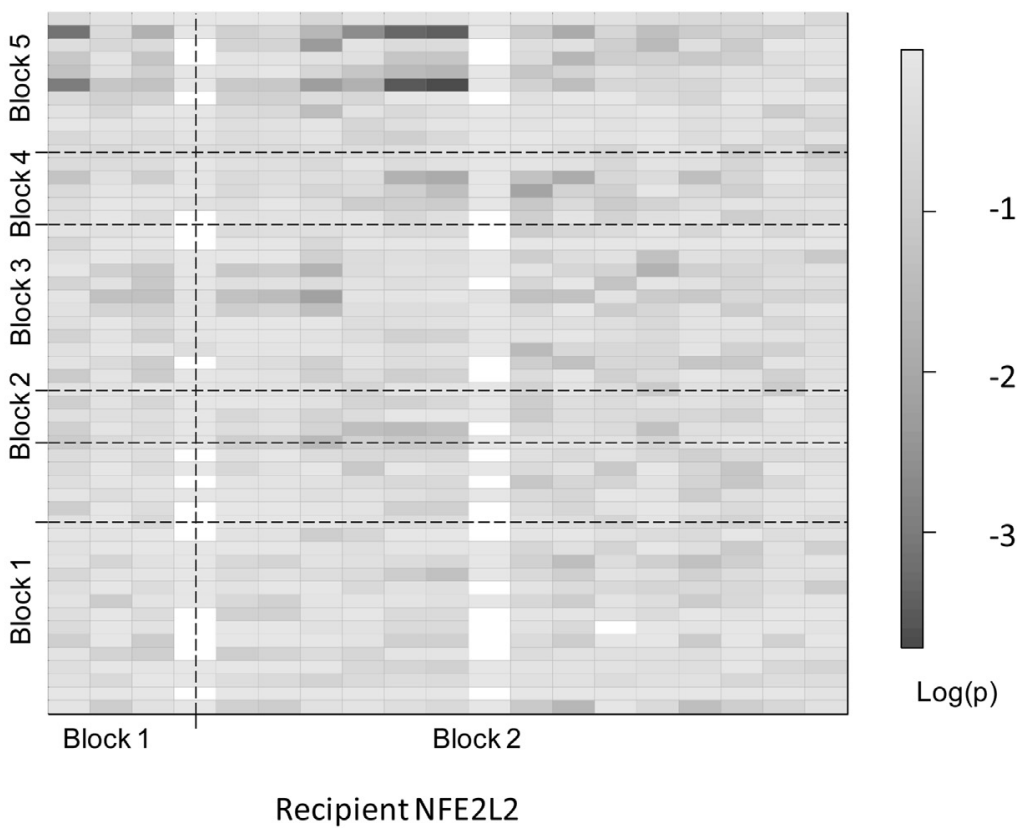

FIGURE 2. SNP set block interaction. Individual SNPs are represented by a rectangle. Blocks are delineated by dotted lines. The highest intensities are evident in donor NOX3 block 3 with recipient NFE2L2 block 1 and in donor NOX3 block 3 with recipient NFE2L2 blocks 1 and 2. SNP, Single nucleotide polymorphism. 
underway by our group and others to standardize prospective sample collection in order to develop cohorts from which validation of identified genetic variants and pathways important in PGD can be tested. Given the many possible confounding factors inherent in lung transplantation and the modest effects of potential factors, only large multiinstitutional cohort studies will have enough statistical power to clarify the effects of these identified factors.

In summary, we have demonstrated an association between genes regulating oxidative stress and PGD. The effects of these associations suggest the importance of oxidant stress detoxifiers in lung recipients and ROS generators in lung donors. The effects of their interaction suggest a complex mechanism of injury of which oxidant stress is a component and therefore should stimulate further inquiry into the participation of GPX1, NFE2L2, NOX3, $P O N 1$, and GSTM2 in the pathogenesis of PGD. In addition, if validated, these gene variants may allow improved risk stratification of transplant recipients for therapies targeted at oxidant balance.

We would like to acknowledge E.J. Demissie for coordinating all data collection efforts for the LTOG study investigators.

Participating centers and investigators in the Lung Transplant Outcomes Group: University of Pennsylvania (coordinating site): Jason Christie, MD, MS (principal investigator), Steven M. Kawut, MD, MS, Ejigayehu Demissie, MSN, Robert M. Kotloff, MD, Vivek N. Ahya, MD, James Lee, MD, MS, Denis Hadjiliadis, MD, MHS, Melanie Rushefski, BS, Richard Aplenc, MD, Clifford Deutschman, MD, MS, Benjamin Kohl, MD, Edward Cantu, MD, Yoshikazu Suzuki, MD, MS, Joshua M. Diamond, MD, MS, Rupal J. Shah, MD, and Laurel Kalman. Columbia University: David Lederer, MD, MS (principal investigator), Selim Arcasoy, MD, Joshua Sonett, MD, Jessie Wilt, MD, Frank D’Ovidio, MD, Lori Shah, MD, Hilary Robbins, MD, Matthew Sacchetti, MD, Nilani Ravichandran, NP, Genevieve Reilly, NP, Jeffrey Koon, MD, Debbie Rybak, BA, Michael Koeckert, BA, Robert Sorabella, BA, Nisha Ann Philip, MBBS, Nadine Al-Naamani, MD, Matthew LaVelle, BS, Megan Larkin, MPH, and Shefali Sanyal, BS. Vanderbilt University: Lorraine Ware, MD (principal investigator), Aaron Milstone, MD (principal investigator), Jean Barnes, RN, Stephanie Logan, RN, Carla Ramsey, RN, Thelma Walden, and Shaquita Claybrooks, RN. Stanford University: Ann Weinacker, MD (principal investigator), Susan Spencer Jacobs, MSN, Val Scott, MSN, and Tal Alfasi, MS. University of Alabama, Birmingham: Keith Wille, MD (principal investigator), and Necole Harris, RN. Johns Hopkins University: Jonathan Orens, MD (principal investigator), Ashish Shah, MD, John McDyer, MD, Christian Merlo, MD, MPH, Matthew Pipeling, MD, Reda Girgis, MD, Karen Oakjones, RN, and April Thurman. University of Michigan: Vibha Lama, MD, MS (principal investigator), Fernando Martinez, MD, MS, Emily Galopin, Douglas R. Armstrong RN, MS, and Mary Maliarik, BS. Duke University: Scott M. Palmer, MD, MHS (principal investigator), David Zaas, MD, MBA, R. Duane Davis, MD, Ashley Finlen-Copeland, MSW, Jessica Martissa, and William A. Davis. University of Chicago: Sangeeta Bhorade, MD (principal investigator), and Mark Lockwood, RN, MSN. University of Pittsburgh: Maria Crespo, MD (principal investigator), Joseph Pilewski, MD, Christian Bermudez, MD, and Kathleen Hanze. Indiana University: David S. Wilkes, MD, David Wilson Roe, MD, Thomas Wozniak, MD, Ronda L. McNamee, RN, Kim A. Fox, RN, Danyel F. Gooch, RN, and Tonya Isaacs, RN.

\section{References}

1. Christie JD, Carby M, Bag R, Corris P, Hertz M, Weill D, et al. Report of the ISHLT Working Group on Primary Lung Graft Dysfunction Part II: Definition. A consensus statement of the International Society for Heart and Lung Transplantation. J Heart Lung Transplant. 2005;24:1454-9.

2. Christie JD, Edwards LB, Kucheryavaya AY, Aurora P, Dobbels F, Kirk R, et al. The registry of the International Society for Heart and Lung Transplantation: Twenty-seventh official adult lung and heart-lung transplant report-2010. J Heart Lung Transplant. 2010;29:1104-18.

3. Suzuki Y, Cantu E, Christie JD. Primary graft dysfunction. Semin Respir Crit Care Med. 2013;34:305-19.

4. Daud SA, Yusen RD, Meyers BF, Chakinala MM, Walter MJ, Aloush AA, et al. Impact of immediate primary lung allograft dysfunction on bronchiolitis obliterans syndrome. Am J Respir Crit Care Med. 2007;175:507-13.

5. Zhang YX, Fan H, Shi Y, Xu ST, Yuan YF, Zheng RH, et al. Prevention of lung ischemia-reperfusion injury by short hairpin RNA-mediated caspase-3 gene silencing. J Thorac Cardiovasc Surg. 2010;139:758-64.

6. de Perrot M, Liu M, Waddell TK, Keshavjee S. Ischemia-reperfusion-induced lung injury. Am J Respir Crit Care Med. 2003;167:490-511.

7. Williams A, Riise GC, Anderson BA, Kjellstrom C, Schersten H, Kelly FJ Compromised antioxidant status and persistent oxidative stress in lung transplant recipients. Free Radic Res. 1999;30:383-93.

8. Rega FR, Wuyts WA, Vanaudenaerde BM, Jannis NC, Neyrinck AP, Verleden GM, et al. Nebulized N-acetyl cysteine protects the pulmonary graft inside the non-heart-beating donor. J Heart Lung Transplant. 2005 24:1369-77.

9. Kozower BD, Christofidou-Solomidou M, Sweitzer TD, Muro S, Buerk DG, Solomides CC, et al. Immunotargeting of catalase to the pulmonary endothelium alleviates oxidative stress and reduces acute lung transplantation injury. Nat Biotechnol. 2003;21:392-8.

10. Marzec JM, Christie JD, Reddy SP, Jedlicka AE, Vuong H, Lanken PN, et al Functional polymorphisms in the transcription factor NRF2 in humans increase the risk of acute lung injury. FASEB J. 2007;21:2237-46.

11. Arcaroli JJ, Hokanson JE, Abraham E, Geraci M, Murphy JR, Bowler RP, et al. Extracellular superoxide dismutase haplotypes are associated with acute lung injury and mortality. Am J Respir Crit Care Med. 2009;179:105-12.

12. Forsberg L, de Faire U, Morgenstern R. Oxidative stress, human genetic variation, and disease. Arch Biochem Biophys. 2001;389:84-93.

13. Christie JD, Robinson N, Ware LB, Plotnick M, De Andrade J, Lama V, et al. Association of protein $\mathrm{C}$ and type 1 plasminogen activator inhibitor with primary graft dysfunction. Am J Respir Crit Care Med. 2007;175:69-74.

14. Christie JD, Shah CV, Kawut SM, Mangalmurti N, Lederer DJ, Sonett JR, et al Plasma levels of receptor for advanced glycation end products, blood transfusion, and risk of primary graft dysfunction. Am J Respir Crit Care Med. 2009;180 1010-5.

15. Covarrubias M, Ware LB, Kawut SM, De Andrade J, Milstone A, Weinacker A, et al. Plasma intercellular adhesion molecule-1 and von willebrand factor in primary graft dysfunction after lung transplantation. Am J Transplant. 2007;7:2573-8.

16. Diamond JM, Meyer NJ, Feng R, Rushefski M, Lederer DJ, Kawut SM, et al Variation in PTX3 is associated with primary graft dysfunction after lung transplantation. Am J Respir Crit Care Med. 2012;186:546-52.

17. Diamond JM, Akimova T, Kazi A, Shah RJ, Cantu E, Feng R, et al. Genetic variation in the prostaglandin E2 pathway is associated with primary graft dysfunction. Am J Respir Crit Care Med. 2014;189:567-75.

18. Christie JD, Kotloff RM, Pochettino A, Arcasoy SM, Rosengard BR, Landis JR, et al. Clinical risk factors for primary graft failure following lung transplantation. Chest. 2003;124:1232-41.

19. Diamond JM, Lee JC, Kawut SM, Shah RJ, Localio AR, Bellamy SL, et al. Clinical risk factors for primary graft dysfunction after lung transplantation. Am J Respir Crit Care Med. 2013;187:527-34. 
20. Christie JD, Van Raemdonck D, de Perrot M, Barr M, Keshavjee S, Arcasoy S, et al. Report of the ISHLT Working Group on Primary Lung Graft Dysfunction Part I: Introduction and methods. J Heart Lung Transplant. 2005;24:1451-3.

21. Christie JD, Bellamy S, Ware LB, Lederer D, Hadjiliadis D, Lee J, et al. Construct validity of the definition of primary graft dysfunction after lung transplantation. J Heart Lung Transplant. 2010;29:1231-9.

22. Keating BJ, Tischfield S, Murray SS, Bhangale T, Price TS, Glessner JT, et al. Concept, design and implementation of a cardiovascular gene-centric $50 \mathrm{k}$ SNP array for large-scale genomic association studies. PLoS One. 2008;3:e3583.

23. Purcell S, Neale B, Todd-Brown K, Thomas L, Ferreira MA, Bender D, et al. Plink: a tool set for whole-genome association and population-based linkage analyses. Am J Hum Genet. 2007;81:559-75.

24. Gabriel SB, Schaffner SF, Nguyen H, Moore JM, Roy J, Blumenstiel B, et al. The structure of haplotype blocks in the human genome. Science. 2002;296:2225-9.

25. Wu MC, Kraft P, Epstein MP, Taylor DM, Chanock SJ, Hunter DJ, et al. Powerful SNP-set analysis for case-control genome-wide association studies. Am J Hum Genet. 2010;86:929-42.

26. Meyer NJ, Li M, Feng R, Bradfield J, Gallop R, Bellamy S, et al. Angpt2 genetic variant is associated with trauma-associated acute lung injury and altered plasma angiopoietin-2 isoform ratio. Am J Respir Crit Care Med. 2011;183:1344-53.
27. Musani SK, Shriner D, Liu N, Feng R, Coffey CS, Yi N, et al. Detection of gene x gene interactions in genome-wide association studies of human population data. Hum Hered. 2007;63:67-84.

28. Hamanishi T, Furuta H, Kato H, Doi A, Tamai M, Shimomura H, et al. Functional variants in the glutathione peroxidase-1 (GPx-1) gene are associated with increased intima-media thickness of carotid arteries and risk of macrovascular diseases in Japanese type 2 diabetic patients. Diabetes. 2004; 53:2455-60.

29. Goyette P, Lefebvre C, Ng A, Brant SR, Cho JH, Duerr RH, et al. Gene-centric association mapping of chromosome 3p implicates MST1 in IBD pathogenesis. Mucosal Immunol. 2008;1:131-8.

30. Fridley BL, Biernacka JM. Gene set analysis of SNP data: benefits, challenges, and future directions. Eur J Hum Genet. 2011;19:837-43.

31. Cho HY, Reddy SP, Kleeberger SR. Nrf2 defends the lung from oxidative stress. Antioxid Redox Signal. 2006;8:76-87.

32. Lubos E, Mahoney CE, Leopold JA, Zhang YY, Loscalzo J, Handy DE. Glutathione peroxidase-1 modulates lipopolysaccharide-induced adhesion molecule expression in endothelial cells by altering CD14 expression. FASEB J. 2010; 24:2525-32.

33. Barrett JC, Fry B, Maller J, Daly MJ. Haploview: analysis and visualization of LD and haplotype maps. Bioinformatics. 2005;21:263-5.

\section{EDITORIAL COMMENTARY}

\section{One step closer to the elimination of primary graft dysfunction}

Eric J. Charles, MD, and Irving L. Kron, MD

See related article on pages 596-602.

Primary graft dysfunction (PGD) is a significant cause of morbidity and mortality after lung transplants. As supported by the findings in the study published by Cantu and colleagues ${ }^{1}$ in this issue of the Journal, as many as $30 \%$ of patients will have development of grade 3 PGD, defined by a $\mathrm{PaO}_{2}$ to inspired oxygen fraction ratio less than 200 along with diffuse allograft infiltrates on chest radiography. Implicated in PGD is ischemia-reperfusion injury, which our laboratory has studied and published on extensively, as well as activation of the oxidant stress pathway. Although studies have shown that genetic variations alter the risk of acute lung injury, there are few data on human subjects describing the genes responsible for PGD after lung transplants. This article examines genetic variations associated with PGD in both donors and recipients of transplanted lungs.

From the Department of Surgery, University of Virginia Health System, Charlottesville, Va.

Disclosures: Authors have nothing to disclose with regard to commercial support. Received for publication Sept 30, 2014; accepted for publication Oct 1, 2014; available ahead of print Nov 7, 2014.

Address for reprints: Irving L. Kron, MD, University of Virginia Health System, TCV Surgery, PO Box 801359, Charlottesville, VA 22908 (E-mail: ilk@virginia.edu). J Thorac Cardiovasc Surg 2015;149:602-3

$0022-5223 / \$ 36.00$

Copyright (c) 2015 by The American Association for Thoracic Surgery http://dx.doi.org/10.1016/j.jtcvs.2014.10.010

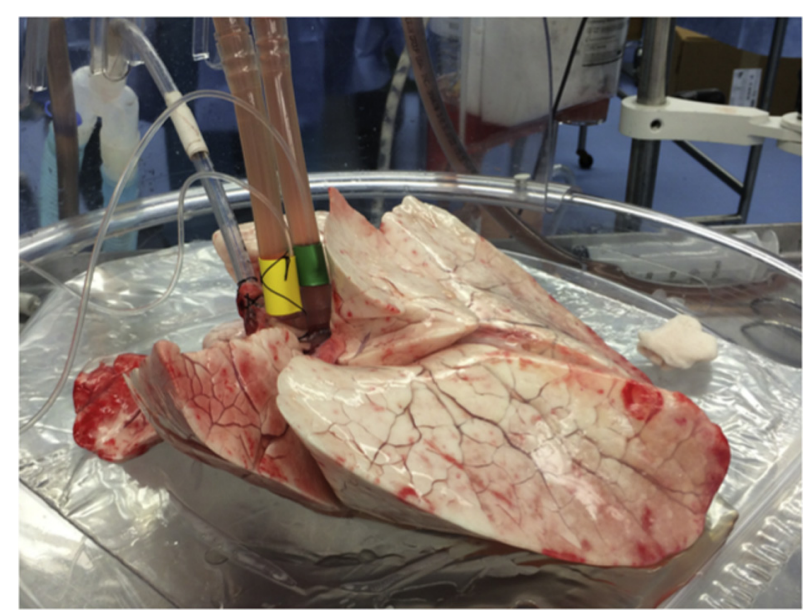

FIGURE 1. Lungs from a porcine donor without a beating heart undergoing rehabilitation with ex vivo lung perfusion.

Cantu and colleagues ${ }^{1}$ completed a large, multicenter prospective cohort study of lung transplant donors and recipients selected from the Lung Transplant Outcomes Group. DNA samples from 1038 lung transplant recipients and 392 lung donors were analyzed for the presence of 49 oxidant stress genes with single-nucleotide polymorphism set analysis. The data demonstrated that GPX1, NFE2L2, NOS3, GSTM2, NOX3, $N O S 1 A P$, and PON1 were associated with grade 3 PGD and 


\section{APPENDIX E1. STATISTICAL METHODS FOR SNP} SET ANALYSIS

For a given individual $\mathrm{i}$, we use $Y_{i}$ to denote the PGD, $x_{i 1}, \ldots, x_{i m}$ to denote the adjusted covariates, and $z_{i 1}, \ldots, z_{i p}$ the $p$ coded SNPs within a test set. The SKAT tests the hypothesis that $h\left(z_{1}, z_{2}, \ldots, z_{p}\right)=0$, in the semiparametric model

$$
\begin{aligned}
\log \operatorname{it}\left\{P\left(Y_{i}=1\right)\right\}= & \beta_{0}+\beta_{1} x_{i 1}+\cdots+\beta_{m} x_{i m}+ \\
& h\left(z_{i 1}, z_{i 2}, \ldots, z_{i p}\right), \quad \mathrm{I}=1, \ldots, \mathrm{n}
\end{aligned}
$$

where $\beta_{0}, \beta_{1}, \ldots, \beta_{m}$ are unknown parameters, measuring the covariates effects, and $h(\cdot)$ is an unknown function, summarizing the joint effect of SNPs $z_{i 1}, \ldots, z_{i p}$ on the PGD. $h(\cdot)$ can be written as $h\left(z_{i 1}, z_{i 2}, \ldots, z_{i p}\right)=\sum_{j=1}^{n} \gamma_{\mathrm{jK}\left(z_{i}, z_{j}\right)}$ where $K(.,$.$) is a user-$ specified positive semidefinite kernel function and coefficients $\gamma_{1}, \ldots, \gamma_{\mathrm{n}}$ are determined by the data. ${ }^{31}$ A score test statistic can be formulated as a function of the phenotype similarity and the kernel function $K(.,$.$) , the genotype$ similarity of 2 individuals, and can be calculated under the null hypothesis without estimating the coefficients $\gamma_{1}, \ldots, \gamma_{n}$. Although there are multiple choices of kernel functions, previous findings demonstrate that the IBS and quadratic kernels have much improved power over the linear kernel in the presence of epistasis. ${ }^{22}$ 


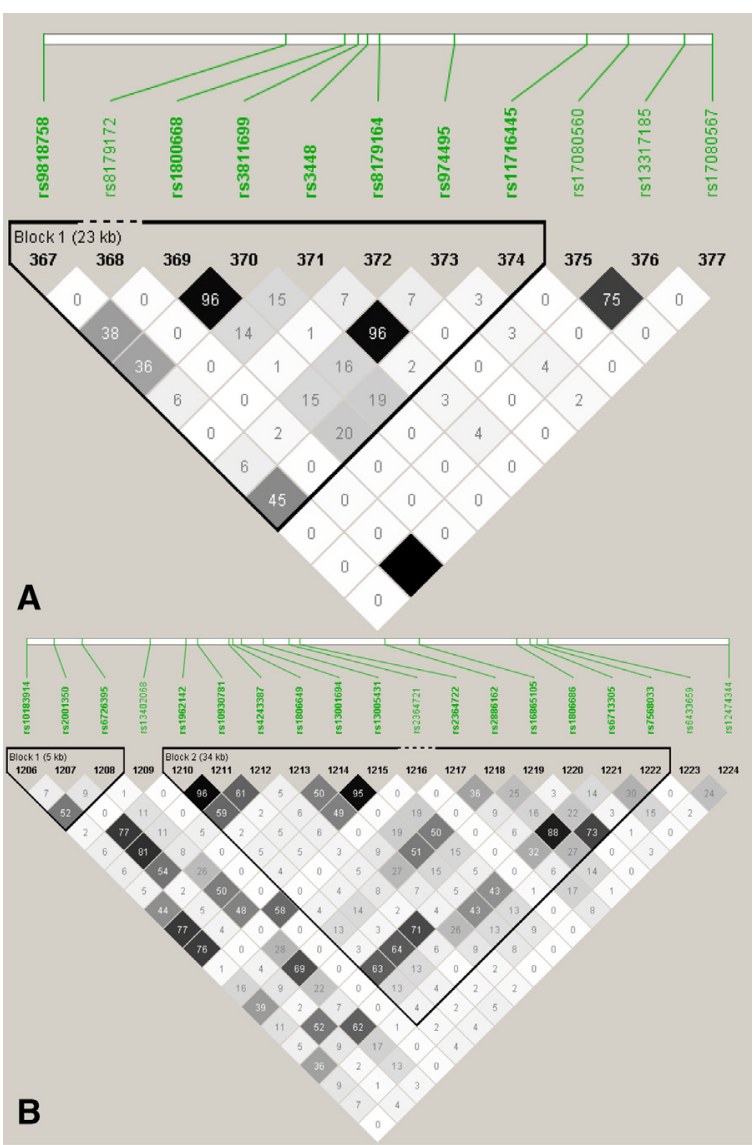

FIGURE E1. Visualization of linkage disequilibrium. Individual SNPs within GPX1 (A) and NFE2L2 (B) were examined using Haploview software. ${ }^{33}$ GPX1 demonstrated more LD blocks than NFE2L2 using the methodology of Gabriel and colleagues. ${ }^{23}$ A block is created if $95 \%$ of informative (ie, noninconclusive) comparisons are strong LD. This method by default ignores markers with $\mathrm{MAF}<0.05$.
TABLE E1. Oxidant stress pathway genes*

\begin{tabular}{|c|c|}
\hline Genes & Proteins \\
\hline$C A T$ & Catalase \\
\hline$C Y B A$ & Cytochrome $b-245, \alpha$ polypeptide chain \\
\hline$C Y B B$ & Cytochrome $b-245, \beta$ polypeptide chain \\
\hline DUSP1 & Dual specificity protein phosphatase 1 \\
\hline ЕРHX2 & Epoxide hydrolase 2 \\
\hline$G P X 1$ & Glutathione peroxidase 1 \\
\hline$G P X 2$ & Glutathione peroxidase 2 \\
\hline$G P X 3$ & Glutathione peroxidase 3 \\
\hline$G P X 4$ & Glutathione peroxidase 4 \\
\hline GPX5 & Glutathione peroxidase 5 \\
\hline GPX6 & Glutathione peroxidase 6 \\
\hline$G P X 7$ & Glutathione peroxidase 7 \\
\hline GSS & Glutathione synthetase \\
\hline GSTA1 & Glutathione $S$-transferase $\alpha 1$ \\
\hline GSTM1 & Glutathione $S$-transferase $\mu 1$ \\
\hline GSTM2 & Glutathione $S$-transferase $\mu 2$ \\
\hline GSTM3 & Glutathione $S$-transferase $\mu 3$ \\
\hline GSTM5 & Glutathione $S$-transferase $\mu 5$ \\
\hline GSTO1 & Glutathione $S$-transferase $\omega 1$ \\
\hline GSTO2 & Glutathione $S$-transferase $\omega 2$ \\
\hline GSTP1 & Glutathione $S$-transferase $\pi 1$ \\
\hline GSTT1 & Glutathione $S$-transferase $\theta 1$ \\
\hline HMOX1 & Heme oxygenase (decycling) 1 \\
\hline$M P O$ & Myeloperoxidase \\
\hline MPV17 & Mitochondrial inner membrane protein \\
\hline$M S R A$ & Methionine sulfoxide reductase A \\
\hline$N C F 2$ & Neutrophil cytosolic factor 2 \\
\hline NCF4 & Neutrophil cytosolic factor 4 \\
\hline$N F E 2 L 2$ & Nuclear factor (erythroid-derived 2)-like 2 \\
\hline$N F K B 1$ & $\begin{array}{l}\text { Nuclear factor of } \kappa \text { light polypeptide gene } \\
\text { enhancer in B cells } 1\end{array}$ \\
\hline NOS1 & Nitric oxide synthase 1 \\
\hline NOS1AP & Nitric oxide synthase 1 adaptor protein \\
\hline$N O S 2 A$ & Nitric oxide synthase $2 \mathrm{~A}$, inducible \\
\hline NOS3 & Nitric oxide synthase 3 \\
\hline NOX3 & $\begin{array}{l}\text { Reduced nicotinamide adenine dinucleotide } \\
\text { phosphate oxidase } 3\end{array}$ \\
\hline NOX4 & $\begin{array}{l}\text { Reduced nicotinamide adenine dinucleotide } \\
\text { phosphate oxidase } 4\end{array}$ \\
\hline$N Q O 1$ & $\begin{array}{l}\text { Reduced nicotinamide adenine dinucleotide } \\
\text { (phosphate) dehydrogenase (quinone) } 1\end{array}$ \\
\hline PIP3-E & Phosphoinositide-binding protein 3-E \\
\hline PON1 & Paraoxonase 1 \\
\hline PON2 & Paraoxonase 2 \\
\hline PON3 & Paraoxonase 3 \\
\hline$S E L S$ & Selenoprotein S \\
\hline$S F T P D$ & Surfactant (pulmonary-associated) protein D \\
\hline SIRT2 & $\begin{array}{l}\text { Nicotinamide adenine dinucleotide-dependent } \\
\text { deacetylase sirtuin } 2\end{array}$ \\
\hline SOD1 & Superoxide dismutase 1 \\
\hline SOD2 & Mitochondrial superoxide dismutase 2 \\
\hline SOD3 & Extracellular superoxide dismutase 3 \\
\hline$T T N$ & Titin \\
\hline TXNRD2 & Thioredoxin reductase 2 \\
\hline
\end{tabular}

*In addition to known classic oxidant stress genes, additional genes were identified through gene ontology and literature searches. 
TABLE E2. Individual donor/recipient single nucleotide polymorphism interactions

\begin{tabular}{|c|c|c|c|c|c|c|c|c|c|}
\hline \multicolumn{2}{|c|}{ SNP } & \multicolumn{3}{|c|}{ Donor } & \multicolumn{3}{|c|}{ Recipient } & \multicolumn{2}{|c|}{ Statistics } \\
\hline Donor & Recipient & Block & Gene & Function & Block & Gene & Function & OR_INT & $P$ \\
\hline rs 163007 & rs13005431 & 5 & NOX3 & Intron & 2 & $N F E 2 L 2$ & Intron & 0.3025 & .00019 \\
\hline rs 163007 & rs13001694 & 5 & NOX3 & Intron & 2 & $N F E 2 L 2$ & Intron & 0.3093 & .00029 \\
\hline rs151223 & rs10183914 & 5 & NOX3 & Intron & 1 & NFE2L2 & Intron & 0.3292 & .00099 \\
\hline rs 163007 & rs 4243387 & 5 & NOX3 & Intron & 2 & $N F E 2 L 2$ & Intron & 3.591 & .00551 \\
\hline rs17086264 & rs 1806649 & 5 & NOX3 & Intron & 2 & NFE2L2 & Intron & 0.4149 & .01738 \\
\hline rs10223752 & rs13005431 & 5 & NOX3 & Intron & 2 & NFE2L2 & Intron & 3.106 & .02495 \\
\hline rs11961314 & rs13001694 & 5 & $N O X 3$ & Intron & 2 & NFE2L2 & Intron & 2.949 & .03266 \\
\hline rs11963380 & rs4243387 & 5 & $N O X 3$ & Intron & 2 & NFE2L2 & Intron & 0.3273 & .04277 \\
\hline rs11963380 & rs6726395 & 3 & $N O X 3$ & Intron & 1 & NFE2L2 & Intron & 0.4406 & .04875 \\
\hline rs11963380 & rs2001350 & 3 & NOX3 & Intron & 1 & NFE2L2 & Intron & 0.113 & .04897 \\
\hline
\end{tabular}

OR_INT, Odds ratio for interaction.

TABLE E3. Individual single nucleotide polymorphisms associated with primary graft dysfunction

\begin{tabular}{|c|c|c|c|c|c|c|c|c|c|}
\hline \multirow[b]{2}{*}{ Cohort } & \multirow[b]{2}{*}{ SNP } & \multicolumn{2}{|c|}{ All } & \multicolumn{2}{|c|}{ No CPB } & \multicolumn{2}{|c|}{ CPB } & \multicolumn{2}{|c|}{ IPF } \\
\hline & & OR & $P$ value & OR & $P$ value & OR & $P$ value & OR & $P$ value \\
\hline \multirow[t]{5}{*}{ Recipient } & rs9818758 & 0.74 & .048 & 0.60 & .011 & 0.91 & .672 & 0.86 & .475 \\
\hline & rs1800668 & 0.74 & .012 & 0.62 & .003 & 0.92 & .608 & 0.86 & .333 \\
\hline & rs3811699 & 0.72 & .006 & 0.62 & .003 & 0.92 & .596 & 0.89 & .465 \\
\hline & rs6726395 & 0.79 & .029 & 0.84 & .217 & 0.73 & .034 & 0.85 & .237 \\
\hline & rs1806649 & 0.76 & .049 & 0.82 & .242 & 0.62 & .018 & 0.82 & .265 \\
\hline \multirow[t]{5}{*}{ Donor } & rs3749930 & 0.38 & .006 & 0.59 & .230 & 0.44 & .025 & 0.24 & .004 \\
\hline & rs 231956 & 1.49 & .024 & 1.52 & .077 & 1.32 & .226 & 1.16 & .530 \\
\hline & rs 13207865 & 1.57 & .024 & 2.23 & .004 & 1.24 & .424 & 1.63 & .083 \\
\hline & rs 231948 & 0.57 & .037 & 1.76 & .012 & 1.27 & .280 & 1.46 & .098 \\
\hline & rs1546894 & 0.31 & .029 & 0.30 & .117 & 0.35 & .091 & 0.43 & .187 \\
\hline
\end{tabular}

